\title{
Large paracetamol overdose - higher dose NAC is required - CON
}

\author{
Ruben Thanacoody ${ }^{1}$ \\ ${ }^{1}$ Newcastle University
}

October 16, 2021

\begin{abstract}
Paracetamol overdose is common in developed countries but less than $10 \%$ involve large ingestions exceeding $30 \mathrm{~g}$ or $500 \mathrm{mg} / \mathrm{kg}$. High dose acetylcysteine (NAC) has been proposed in patients taking large paracetamol overdoses based on reports of hepatotoxicity despite early initiation of NAC treatment with the commonly used $300 \mathrm{mg} / \mathrm{kg}$ intravenous acetylcysteine regimen. The evidence from cohorts of patients treated with the standard NAC regimen after large paracetamol overdoses shows that it is effective in most patients. Small studies in patients whose paracetamol concentration are above the $300 \mathrm{mg} / \mathrm{L} \mathrm{nomogram} \mathrm{line}$ show that modification of the standard NAC regimen to provide a total of 400-500 mg/kg NAC over 21-22h may reduce the risk of hepatotoxicity (peak ALT>1000 IU/L) but the impact on development of hepatic failure, liver transplantation and mortality with this approach is presently unknown. Better risk stratification of patients taking paracetamol overdose may allow higher dose NAC and adjunctive treatments such as CYP2E1 inhibition and extracorporeal removal of paracetamol to be targeted to those patients at the highest risk of hepatotoxicity after a large paracetamol overdose.
\end{abstract}

\section{Title: Large paracetamol overdose - higher dose NAC is required $-\mathrm{CON}$}

Author: Dr H K Ruben Thanacoody

Affiliations:

Translational and Clinical Research Institute, Newcastle University, Newcastle-upon-Tyne, UK

National Poisons Information Service (Newcastle unit), The Newcastle-upon-Tyne Hospitals NHS Foundation Trust, UK

Corresponding Author:

Dr H K Ruben Thanacoody MD, FRCP, FRCP(Edin)

Director, National Poisons Information Service (Newcastle unit)

Newcastle upon Tyne

NE2 4AB

United Kingdom

Tel: 00441912824276

Email ruben.thanacoody@ncl.ac.uk

\section{Abstract:}

Paracetamol overdose is common in developed countries but less than $10 \%$ involve large ingestions exceeding $30 \mathrm{~g}$ or $500 \mathrm{mg} / \mathrm{kg}$. High dose acetylcysteine (NAC) has been proposed in patients taking large paracetamol overdoses based on reports of hepatotoxicity despite early initiation of NAC treatment with the commonly 
used $300 \mathrm{mg} / \mathrm{kg}$ intravenous acetylcysteine regimen. The evidence from cohorts of patients treated with the standard NAC regimen after large paracetamol overdoses shows that it is effective in most patients. Small studies in patients whose paracetamol concentration are above the $300 \mathrm{mg} / \mathrm{L}$ nomogram line show that modification of the standard NAC regimen to provide a total of $400-500 \mathrm{mg} / \mathrm{kg}$ NAC over $21-22 \mathrm{~h}$ may reduce the risk of hepatotoxicity (peak ALT>1000 IU/L) but the impact on development of hepatic failure, liver transplantation and mortality with this approach is presently unknown. Better risk stratification of patients taking paracetamol overdose may allow higher dose NAC and adjunctive treatments such as CYP2E1 inhibition and extracorporeal removal of paracetamol to be targeted to those patients at the highest risk of hepatotoxicity after a large paracetamol overdose.

Paracetamol is one of the commonest drugs taken in overdose and a significant cause of acute liver injury in developed countries. The hepatic toxicity of paracetamol results from its metabolic oxidation to a reactive metabolite, N-acetyl-para-benzoquinoneimine metabolite (NAPQI) by cytochrome P450 enzymes when the normal sulphation and glucuronidation detoxification pathways become saturated in overdose. In human liver microsomes, CYP2E1, CYP1A2 and CYP2A6 isoforms have been shown to convert paracetamol to NAPQI, with a reported $\mathrm{Km}$ for the CYP2E1 isoform of 100-200 mg/L. Studies with healthy human volunteers pretreated with the CYP2E1 inhibitor, disulfiram, confirmed the role of CYP2E1 in paracetamol oxidation. It is unclear whether the generation of NAPQI by CYP2E1 follows linear kinetics or is saturable at high paracetamol concentrations.

NAPQI is detoxified by conjugation with glutathione but when endogenous glutathione stores are depleted, NAPQI binds to cysteine groups on cellular proteins to form protein adducts. Intravenous acetylcysteine(NAC) was developed as an antidote to restore glutathione stores. The original total dose $(300 \mathrm{mg} / \mathrm{kg}$ bodyweight) of intravenous NAC, given as three separate infusions (150 mg/kg over 15 minutes, $50 \mathrm{mg} / \mathrm{kg}$ over 4 hours and $100 \mathrm{mg} / \mathrm{kg}$ over 16 hours) was empirical and designed to deliver a high proportion of antidote rapidly. ${ }^{1}$ This fixed weight-based regimen regardless of the paracetamol dose ingested has given rise to much debate about whether it can adequately replenish glutathione following massive paracetamol ingestions.

Rumack \& Bateman reported that a suggested toxic human paracetamol dose of $15.9 \mathrm{~g}$ in an average $70 \mathrm{~kg}$ patient with a $1.5 \mathrm{~kg}$ liver and a paracetamol half-life of $4 \mathrm{~h}$ can be adequately detoxified using the $300 \mathrm{mg} / \mathrm{kg}$ intravenous NAC regimen with a $6.25 \mathrm{mg} / \mathrm{kg} / \mathrm{h}$ infusion in the third infusion. They proposed using these assumptions that a patient ingesting $35 \mathrm{~g}(500 \mathrm{mg} / \mathrm{kg})$ of paracetamol warranted an increase in infusion rate in the third bag to $13.75 \mathrm{mg} / \mathrm{kg} / \mathrm{h} .{ }^{1}$ The median reported dose of paracetamol ingested in large cohort studies of patients treated with NAC in the UK and Australia is around $16 \mathrm{~g}(210-250 \mathrm{mg} / \mathrm{kg})$ but the rates of hepatotoxicity (defined as peak ALT $>1000 \mathrm{IU} / \mathrm{L}$ ) is only around 4-8\%, depending on the nomogram used to determine treatment ${ }^{2,3}$, suggesting that the vast majority of patients ingesting $>16 \mathrm{~g}$ paracetamol fare well with the current $300 \mathrm{mg} / \mathrm{kg}$ NAC dose. Hendrickson used similar stoichiometric calculations to propose infusion rates of $12.5,18.75$ and $25 \mathrm{mg} / \mathrm{kg} / \mathrm{h}$ for patients above the $300 \mathrm{mg} / \mathrm{L}, 450 \mathrm{mg} / \mathrm{L}$ and $600 \mathrm{mg} / \mathrm{L}$ nomogram lines respectively. ${ }^{4}$ These theoretical calculations for the "average" patient assuming linear paracetamol pharmacokinetics most likely overestimate the infusion rate required in most patients as they do not account for the large inter-individual variability in metabolic clearance of paracetamol in overdose resulting from differences in glucuronidation, sulphation and CYP2E1 capacity which influence the paracetamol half-life.

Several studies have consistently reported a concentration-dependent increase in risk of hepatotoxicity (peak ALT $>1000 \mathrm{IU} / \mathrm{L}$ ) in patients despite early treatment with acetylcysteine. Overall $3.6-4.3 \%$ of patients in large cohort studies in the $\mathrm{UK}^{3,5,6}$ and $8 \%$ in Australia ${ }^{2}$ develop hepatotoxicity but a graded increase at higher nomogram-related concentrations is observed, with reported rates of hepatotoxicity of $10.2-15 \%$ and $13.6-30.8 \%$ in those patients with a $4 \mathrm{~h}$ extrapolated paracetamol concentration greater than $300 \mathrm{mg} / \mathrm{L}$ and $500 \mathrm{mg} / \mathrm{L}$ respectively. ${ }^{5,6}$ A recent retrospective review of 104 massive paracetamol overdoses treated with the standard $21 \mathrm{~h}$ NAC regimen from a US poison centre reported hepatotoxicity in 25 cases $(24 \%)$, of which 9 cases $(14 \%)$ were in the 300-449 mg/L nomogram group, 1 case $(7 \%)$ in the 450-599 mg/L nomogram 
group, and 15 cases $(56 \%)$ in the $>600 \mathrm{mg} / \mathrm{L}$ nomogram group. Only $4 / 44(9 \%)$ who were treated within $8 \mathrm{~h}$ developed hepatotoxicity. ${ }^{7}$ These findings have fuelled the debate over whether higher doses of NAC are required for these perceived "NAC failures" even though all of these patients recovered and no deaths and liver transplants were reported in these large cohorts of patients.

Smilkstein reported in their landmark study using the oral NAC protocol consisting of a $140 \mathrm{mg} / \mathrm{kg}$ loading dose followed by $70 \mathrm{mg} / \mathrm{kg}$ every $4 \mathrm{~h}$ for 17 doses that hepatotoxicity occurred in $2-5 \%$ of all cases that receive $\mathrm{NAC}$ within $8 \mathrm{~h}$ of ingestion even with increasing paracetamol concentrations. The total oral dose administered in the first $21 \mathrm{~h}$ is $490 \mathrm{mg} / \mathrm{kg}$ and is delivered directly to the liver versus the $300 \mathrm{mg} / \mathrm{kg}$ intravenous dose which is dependent on hepatic extraction of NAC from the systemic circulation for efficacy. ${ }^{8}$

The ATOM-2 study, an observational study of massive paracetamol overdose (defined as $40 \mathrm{~g}$ or more ingested over $8 \mathrm{~h}$ or less) in several Australian hospitals, reported that 28/200 (14\%) developed hepatotoxicity (peak ALT > 1000), including 6/200 (3\%) of those treated within $8 \mathrm{~h} .79 / 200$ patients were above the $300 \mathrm{mg} / \mathrm{L}$ nomogram line and were treated within $16 \mathrm{~h}$ of ingestion with either a standard $300 \mathrm{mg} / \mathrm{kg}$ NAC regimen or an increased NAC dose consisting of doubling the dose in the 16 -hourly infusion to $200 \mathrm{mg} / \mathrm{kg}$ (infusion rate $12.5 \mathrm{mg} / \mathrm{kg} / \mathrm{h}$ ), giving a total dose of $400 \mathrm{mg} / \mathrm{kg}$. There was a significant reduction in the rates of hepatotoxicity from $10 / 36(27.7 \%)$ in the standard regimen group to $4 / 43(9.3 \%)$ in the increased NAC regimen (OR 0.27; 95\% CI: 0.08-0.94), with most of the beneficial effect observed in those patients above the triple nomogram line (4h extrapolated concentration of $450 \mathrm{mg} / \mathrm{L}$ ) ${ }^{9}$ It is noteworthy that even in this very small high-risk subgroup of patients ingesting $40 \mathrm{~g}$ paracetamol or more and above the $300 \mathrm{mg} / \mathrm{L}$ nomogram line, almost $75 \%$ of patients did not develop hepatotoxicity with the standard $300 \mathrm{mg} / \mathrm{kg}$ regimen. It is uncertain whether this modified regimen would actually alter clinically important outcomes such as the development of fulminant hepatic failure, liver transplant and deaths. The modified increased dose regimen used in the ATOM-2 study is a pragmatic alteration of the existing $21 \mathrm{~h}$ regimen and it is unclear whether the benefit seen results from an increased total dose of NAC or the increased infusion rate and whether a similar benefit would not have been achieved by a regimen delivering the same total dose with a higher infusion rate.

Such an approach underpins the SNAP regimen which was based on the premise that an optimal NAC regimen should provide an initial loading dose to restore hepatic glutathione stores and an infusion high enough for glutathione synthesis to exceed NAPQI generation for the vast majority of patients. We calculated using probabilistic modelling that a regimen delivering a total dose of $300 \mathrm{mg} / \mathrm{kg}$ with an initial loading dose of $100 \mathrm{mg} / \mathrm{kg}$ over $2 \mathrm{~h}$ followed by $200 \mathrm{mg} / \mathrm{kg}$ over $10 \mathrm{~h}$ (infusion rate $20 \mathrm{mg} / \mathrm{kg} / \mathrm{h}$ ) would be sufficient in most patients. ${ }^{10,11}$ In the small minority of patients with liver injury or persistently elevated paracetamol concentrations, an extension of the $10 \mathrm{~h}$ infusion would provide a $500 \mathrm{mg} / \mathrm{kg}$ total dose over $22 \mathrm{~h} .16 / 105(15.2 \%)$ patients with paracetamol overdose above the $300 \mathrm{mg} / \mathrm{L}$ nomogram line treated within $24 \mathrm{~h}$ of ingestion with the SNAP regimen developed hepatotoxicity, of which 3/40 (7.5\%) and 9/82 (11\%) were treated within $8 \mathrm{~h}$ and $16 \mathrm{~h}$ respectively. All 16 patients who developed hepatotoxicity had evidence of acute liver injury $($ ALT $>150)$ at the end of the $12 \mathrm{~h}$ infusion (unpublished data).

There is no agreed definition of a massive overdose, with Marks et $\mathrm{al}^{5}$ and Chiew et al. ${ }^{9}$ using arbitrary cut-offs of 30 and $40 \mathrm{~g}$ or an extrapolated $4 \mathrm{~h}$ paracetamol concentration above $250 \mathrm{mg} / \mathrm{L}$ and $300 \mathrm{mg} / \mathrm{L}$ respectively and Hendrickson et $\mathrm{al}^{4}$ suggesting a dose of $32 \mathrm{~g}$ or a paracetamol concentration above the $300 \mathrm{mg} / \mathrm{L}$ nomogram line. It is also difficult to define precisely which group of patients might benefit from an increased dose of NAC and the optimal way of delivering this higher dose. Bateman and Dear suggested that those who may require a high dose NAC regimen include doses above $500 \mathrm{mg} / \mathrm{kg}$ bodyweight paracetamol, a nomogram concentration above the $500 \mathrm{mg} / \mathrm{L}$ line for those with ingestions over a shorter time (e.g less than $2 \mathrm{~h}$ ), or a dose likely to result in mitochondrial paralysis $(\sim 1 \mathrm{~g} / \mathrm{kg}) \cdot{ }^{12}$ However, in the presence of mitochondrial dysfunction associated with paracetamol concentrations greater than $900 \mathrm{mg} / \mathrm{L}$, extracorporeal treatment to enhance clearance of paracetamol is recommended by the EXTRIP international panel. ${ }^{13}$ The anecdotal use of fomepizole as a CYP2E1 inhibitor in conjunction with haemodialysis and NAC has also been reported following massive paracetamol overdose. Although the evidence for benefit of higher NAC dose is scanty, 
pending newer evidence which is difficult to generate for this small subset of patients, the most recent guidelines in Australia and New Zealand pragmatically recommend doubling the concentration of the 16hour infusion of NAC from $100 \mathrm{mg} / \mathrm{kg}$ to $200 \mathrm{mg} / \mathrm{kg}$ (giving a total of $400 \mathrm{mg} / \mathrm{kg}$ over $21 \mathrm{~h}$ ) in patients who ingest more than $30 \mathrm{~g}$ or $500 \mathrm{mg} / \mathrm{kg}$ and in those with a paracetamol concentration more than the $300 \mathrm{mg} / \mathrm{L}$ nomogram line. ${ }^{14}$ Clinicians treating these patients need to balance the potential benefit in up to $15 \%$ of these high-risk patients against the risk of administration errors with a change of regimen in some patients. An alternative approach which appears similarly effective is an extension of the $10 \mathrm{~h}$ infusion in those patients with abnormal ALT or persistently elevated paracetamol concentrations at the end of the $12 \mathrm{~h}$ SNAP regimen.

It is evident from several large patient cohorts that most patients with large paracetamol overdoses do well with the $300 \mathrm{mg} / \mathrm{kg}$ intravenous NAC regimen (whether given over $12 \mathrm{~h}$ or $21 \mathrm{~h}$ ) and do not require high dose NAC. There will undoubtedly be a small proportion of patients with either abnormally low glucuronidation and sulphation capacity, high CYP2E1 activity or low gluthathione stores who may benefit from higher NAC dose or adjunctive treatments. Further research is required to assess the effectiveness of modified NAC regimens, CYP2E1 inhibition, extracorporeal elimination either alone or in combination in at-risk patients. Better risk stratification of patients with paracetamol overdose at presentation to identify those at high risk of developing hepatotoxicity would facilitate multi-centre prospective studies to evaluate the optimal strategy for managing this small subset of high-risk patients with a view to improving clinically important outcomes other than a historically determined clinical endpoint of peak ALT $>1000$. Novel biomarkers including mir-122 and paracetamol adduct concentration at presentation have been shown to predict subsequent development of hepatotoxicity. ${ }^{15,16}$ The development of point-of-care tests that can quantify paracetamol concentration, ALT and novel biomarkers would be a major advance in facilitating such stratified trials in future.

\section{References}

1. Rumack BH, Bateman DN. Acetaminophen and acetylcysteine dose and duration: past, present and future. Clin Toxicol 2012; 50: 91-98.

2. Wong A, Isbister G, McNulty R, et al. Efficacy of a two bag acetylcysteine regimen to treat paracetamol overdose (2NAC study). EClinicalMedicine 2020; 20: 100288.

3. Pettie JM, Caparrotta TM, Hunter RW et al. Safety and efficacy of the SNAP 12h acetylcysteine regimen for the treatment of paracetamol overdose. EClinicalMedicine 2019; 11: 11-7.

4. Hendrickson RG. What is the most appropriate dose of N-acetylcysteine after massive acetaminophen overdose? Clin Toxicol 2019; 57(8): 686-691.

5. Cairney DG, Beckwith HKS, Al-Hourani K, et al. Plasma paracetamol concentration at hospital presentation has a dose-dependent relationship with liver injury despite prompt treatment with intravenous acetylcysteine. Clin Toxicol 2016; 54: 405-410.

6. Marks DJ, Dargan PI, Archer JR, et al. Outcomes from massive paracetamol overdose: a retrospective observational study. Br J Clin Pharmacol 2017; 83(6): 1263-1272.

7. Downs JW, Cumpston KL, Kershner EK, et al. Clinical outcome of massive acetaminophen overdose treated with standard dose N-acetylcysteine. Clin Toxicol 2021; 59(10): 932-936.

8. Smilkstein MJ, Knapp GL, Kulig KW, Rumack BH. Efficacy of oral N-acetylcysteine in the treatment of acetaminophen overdose. Analysis of the national multicenter study (1976 to 1985). The New England journal of medicine 1988; 319: 1557-1562.

9. Chiew AL, Isbister GK, Kirby KA, et al. Massive paracetamol overdose: an observational study of the effect of activated charcoal and increased acetylcysteine dose (ATOM-2). Clin Toxicol. 2017; 55(10):10551065.

10. Thanacoody HK, Gray A, Dear JW, et al. Scottish and Newcastle antiemetic pretreatment for paracetamol poisoning study (SNAP). BMC Pharmacol Toxicol 2013; 14:20. 
11. Bateman DN, Dear JW, Thanacoody HK, et al. Reduction of adverse effects from intravenous acetylcysteine treatment for paracetamol poisoning: a randomised controlled trial. Lancet 2014; 383: 697-704.

12. Bateman DN, Dear JW. Should we treat very large paracetamol overdose differently? Br J Clin. Pharmacol 2017; 83: 1163-5.

13. Gosselin S, Juurlink DN, Kielstein JT, et al. Extracorporeal treatment for acetaminophen poisoning: recommendations from the EXTRIP workgroup. Clin Toxicol 2014; 52: 856-867.

14. Chiew AL, Reith D, Pomerleau A, et al. Updated guidelines for the management of paracetamol poisoning in Australia and New Zealand. Med J Aust. 2020; 212(4):175-183.

15. Dear JW, Clarke JI, Francis B, et al. Risk stratification after paracetamol overdose using mechanistic biomarkers: results from two prospective cohort studies. Lancet Gastroenterol Hepatol. 2018; 3(2):104-113.

16. Chiew AL, James LP, Isbister GK, et al. Early acetaminophen-protein adducts predict hepatotoxicity following overdose (ATOM-5). J Hepatol. 2020; 72(3):450-46. 